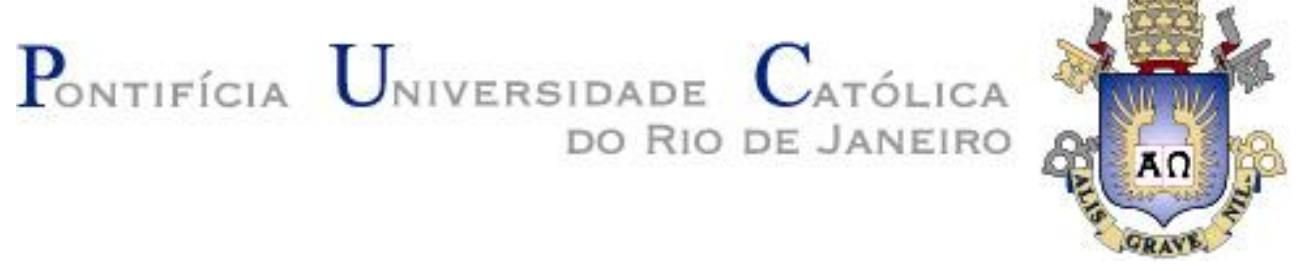

Tiago Batalha de Oliveira

\title{
Elisão Nominal e questões de interface: fronteiras prosódicas
}

\section{Dissertação de Mestrado}

Dissertação apresentada ao Programa de Pós-Graduação em Estudos da Linguagem da PUC-Rio como requisito parcial para obtenção do título de mestre em Estudos da Linguagem.

Orientadora: Prof ${ }^{\text {a }}$. Cilene Aparecida Nunes Rodrigues Coorientadora: Profá. Letícia Maria Sicuro Corrêa 


\section{Tiago Batalha de Oliveira}

\section{Elisão Nominal e questões de interface: \\ fronteiras prosódicas}

Dissertação apresentada ao Programa de Pós-Graduação em Estudos da Linguagem da PUC-Rio como requisito parcial para obtenção do título de mestre em Estudos da Linguagem. Aprovado pela Comissão Examinadora abaixo assinada.

\section{Profa. Cilene Aparecida Nunes Rodrigues \\ Orientadora \\ Departamento de Letras Puc-Rio}

Profa . Letícia Maria Sicuro Corrêa

Coorientadora

Departamento de Letras Puc-Rio

Profa. Érica dos Santos Rodrigues

Departamento de Letras Puc-Rio

Profa. Ruth Elizabeth Vasconcellos Lopes Instituto de Estudos da Linguagem Unicamp/SP

Profa. Denise Berruezo Portinari Coordenadora Setorial do Centro Técnico Científico - PUC-Rio

Rio de Janeiro, 25 de setembro de 2014. 
Todos os direitos reservados. É proibida a reprodução total ou parcial do trabalho sem autorização do autor, das orientadoras e da universidade.

\section{Tiago Batalha de Oliveira}

Graduou-se em Letras Português/Literaturas pela UERJ, em 2006, e obteve o grau de licenciado pela mesma universidade também naquele ano. Participou de diversos congressos e minicursos na área de Linguagem e Cognição e Linguística Gerativa. Áreas de interesse: Linguagem e Cognição, Linguística Gerativa, Fonologia e Prosódia.

Ficha Catalográfica

Oliveira, Tiago Batalha de

Elisão nominal e questões de interface: fronteiras prosódicas / Tiago Batalha de Oliveira ; orientadora: Cilene Aparecida Nunes Rodrigues ; coorientadora: Letícia Maria Sicuro Corrêa. - 2014. 117 f. : il. (color.) ; $30 \mathrm{~cm}$

\section{Dissertação} (mestrado)-Pontifícia Universidade Católica do Rio de Janeiro, Departamento de Letras, 2014. Inclui bibliografia

1. Letras - Teses. 2. Elipse nominal. 3. Interface. 4. Sintaxe-fonologia. 5. Sintaxe gerativa. 6. Fonologia prosódica. 7. Sândi. I. Rodrigues, Cilene Aparecida Nunes. II. Corrêa, Letícia Maria Sicuro. III. Pontifícia Universidade Católica do Rio de Janeiro. Departamento de Letras. IV. Título.

CDD: 400 
In memorian, a Ivo Batalha, Maria do Carmo Batalha Cícero Bezerra e Ivete Lopes pelo amor transmitido às gerações 


\section{Agradecimentos}

À minha orientadora Cilene Rodrigues, com imenso orgulho e admiração, por tudo o que me ensinou nesses dois anos de convívio, pelas portas que me abriu, por me mostrar possibilidades de novos mundos, por provar que é possível fazer ciência 'dura' sem ser duro (com humanidade e sensibilidade) e por não ter me deixado sozinho num 'deserto sem água'...

À minha coorientadora, Letícia Maria Sicuro Corrêa, também com muita admiração, pela disponibilidade, pelo tratamento sempre cortês e pelo exemplo de que ciência se faz com seriedade e dedicação.

À CAPES e à PUC-Rio, pelos auxílios concedidos, sem os quais este trabalho não poderia ter sido realizado.

Aos meus núcleos, Marilsa e Ismael, que, em momento de interface, me trouxeram ao mundo com o DNA do respeito ao próximo como princípio de vida e da curiosidade e paixão pelo conhecimento.

Aos meus principais argumentos, Ártemis e Bernardo, amores eternos da minha vida, por cada sorriso, pela confiança e pela compreensão com minhas quase infinitas ausências.

À Fabiana, a elisão mais presente em minha vida, por ter dividido parte desse sonho e pelo companheirismo, sobretudo, nesses últimos momentos.

Aos meus complementizadores Ismar Batalha e Marcos Paulo Rangel, pelos projetos, pela cumplicidade de todos os momentos e pela força quando necessário. 
À minha correferente Raquel Batalha, pela voz, pela paciência e pela grande parceria de vida.

À minha AgreeP, Ana Cláudia Gonçalves, pelo encorajamento em todas as etapas desse processo e pela possibilidade do encontro único.

Aos adjuntos Elisa Rangel, pelo apoio e entusiasmo, Fátima Sueli e Carlos, pelo exemplo de luta e pela ajuda nos detalhes.

Aos colegas da PUC que, de alguma maneira, contribuíram afetiva ou intelectualmente com este trabalho, com destaque a: Naomi Orton, João Jr., Sabrina Anacleto, Raiane Salles e Ludmila Milhorance.

A Guilherme Cardozo, pela amizade, por ter compartilhado tudo isso lá atrás e pelo suporte fundamental na reta final.

À Juliana Salles, presente eterno da PUC, pelas caronas, trocas e, principalmente, pela leveza.

À Eneida Werner, outro presente da PUC, pelas frases em alemão, pelas histórias e por ter tornado Campinas menos fria.

À Daniele e, sobretudo, à Chiquinha pela generosidade e paciência.

À professora Adriana Nóbrega, pelo ponta-pé inicial.

Aos queridos colegas do Ministério Público, pela integral sensibilidade à importância do mestrado em minha vida, em especial: a Rosildo Pereira; Anderson Ferraz; Jonathan Silva; Dr. Jorge Magno Dra ${ }^{\mathrm{a}}$. Cláudia Portocarrero; Dra Adriana Medeiros; Alexander Mello; e Elisângela Ferreira.

A todos os participantes dos quatro experimentos, peças fundamentais no presente trabalho e principalmente pela estimulante curiosidade. 


\section{Resumo}

Oliveira, Tiago Batalha de; Rodrigues, Cilene Aparecida Nunes; Corrêa, Letícia Maria Sicuro. Elisão Nominal e questões de interface: fronteiras prosódicas. Rio de Janeiro, 2014, 117p. Dissertação de Mestrado Departamento de Letras, Pontifícia Universidade Católica do Rio de Janeiro.

A presente pesquisa investiga condições de interface Sintaxe/Prosódia em estruturas contendo Elipse Nominal (EN). A literatura sobre EN reporta restrições sobre elisão nominal seguida de sintagma preposicionado. Nossa pesquisa investiga essa restrição com base em dados do Português Brasileiro (PB). Nossa hipótese central é a de que a ocorrência de elisão nominal no contexto em questão depende das condições de interface entre a sintaxe e a fonologia (i.e. mapeamento de domínios sintáticos em domínios prosódicos). Para verificação dessa hipótese, foram realizados quatro experimentos, com metodologia de caráter experimental. O primeiro - teste de aceitabilidade com uso de escala - verifica a ocorrência do fenômeno em PB. Os demais experimentos, baseados em teste de reprodução oral, buscaram verificar em que condições sentenças no contexto em exame, consideradas agramaticais no Português Europeu (PE), são licenciadas por falantes nativos do PB. Os resultados indicaram que o licenciamento dessas sentenças está associado ao processo de ajustamento prosódico como resultado da aplicação de processos fonológicos (como sândi) e a manipulação de traços prosódicos (como a duração), no qual o artigo definido, em razão de seu status prosódico frágil, tende a ser apagado. Nossa pesquisa evidencia, portanto, algumas estratégias de reparo utilizadas pelo falante para satisfazer as condições de interface entre a sintaxe e a fonologia. Nesse sentido, esse estudo contribui para um melhor entendimento teórico da Gramática, especificando condições de interface e as relações entre a sintaxe e outros componentes da Gramática.

\section{Palavras-chave}

Elipse nominal; interface: sintaxe-fonologia; sintaxe gerativa; fonologia prosódica; sândi. 


\section{Abstract}

Oliveira, Tiago Batalha de; Rodrigues, Cilene Aparecida Nunes (Advisor); Corrêa, Letícia Maria Sicuro (Co-advisor). Nominal Gapping and interface issues: prosodic boundaries. Rio de Janeiro, 2014, 117p. MSc. Dissertation Departamento de Letras, Pontifícia Universidade Católica do Rio de Janeiro.

This research investigates the interface Syntax/Prosody conditions in structures containing Nominal Gapping (EN from Portuguese 'Elisão Nominal'). The literature about EN reports restrictions about nominal gapping followed by a prepositional phrase. Our research investigates this restriction based on data from Brazilian Portuguese. Our central hypothesis is that the occurrence of nominal gapping in the mentioned context depends on the interface conditions between syntax and phonology (i.e. mapping of syntactic domains in prosodic domains). In order to verify this hypothesis, four experiments were conducted with methodology of experimental carachter. The first - acceptability test with use of scale - verifies the occurrence of the phenomenon in Brazilian Portuguese. Other experiments, based on oral reproduction test, sought to verify in which conditions the sentences in the examined context considered ungrammatical in European Portuguese are accepted by native speakers of Brazilian Portuguese. The results indicated that the licensing of these sentences is associated to the process of prosodic adjustment as result of the application of phonological processes (as sandhi, for instance) and the manipulation of prosodic features (such as duration), in which the definite article, because of its fragile prosodic status, tends to be elided. Our research evidences, therefore, some repair strategies employed by the speakers to satisfy the interface conditions between Syntax and Phonology. Thus, this study contributes for a better theoretical understanding of Grammar, specifying interface conditions and the relations between Syntax and other Grammar components.

\section{Keywords}

Nominal gapping; interface: syntax-phonology; generative syntax; prosodic phonology; sandhi. 


\section{Sumário}

1. Introdução

2. A gramática do vazio 15

2.1. A presença do vazio 15

2.2. O vazio na Gramática Gerativa 20

2.2.1. Tipos de Elipse 20

2.2.2. Contextos de EN 22

2.2.3. Análises não Minimalistas 25

2.2.3.1. Elipses Nominais e Categorias Vazias 27

2.2.3.2. Algumas abordagens sobre EN 33

2.2.4. Análise Minimalista sobre EN 37

2.3. Resumo 39

3. A Elisão Nominal em estudo: uma questão de interface 40

3.1. O problema investigado 40

3.2. O papel da interface sintaxe-fonologia 46

3.3. Fonologia Prosódica 51

3.3.1. Constituintes Prosódicos 53

3.3.2. Noções de fonologia: sílaba, clíticos e seu estatuto 59 prosódico

3.3.3. Processos fonológicos pós-lexicais: sândi e 63 ressilabação

3.3.4. Traços prosódicos e análise acústica dos dados 67

3.4. Resumo 70

4. Experimentos, resultados e análises $\quad 71$

4.1. Experimento 1 - teste de aceitabilidade 71

4.2. Experimento 2 - teste de reprodução oral 77

4.3. Experimento 3 - teste de reprodução oral 83

4.4. Experimento 4 - teste de reprodução oral 91

4.5. Resumo e Consideração Finais 96 
5. Conclusão

6. Referências Bibliográficas

7. Apêndice 